\title{
KNOWLEDGE AND ATTITUDE ABOUT JAPANESE ENCEPHALITIS AND COMMUNITY PARTICIPATION FOR ITS PREVENTION IN SIVASAGAR, ASSAM - A CROSS SECTIONAL SURVEY
}

\author{
Daisy Konwar ${ }^{1 *}$, Pubali Bhuyan', Tousifur Rahman ${ }^{2}$ and Rimen Bordoloi ${ }^{3}$ \\ 1 *Department of Life-sciences, Dibrugarh University, Dibrugarh-786 004, Assam, India \\ daisykonwar85@gmail.com. Phone no.9401201804 \\ ${ }^{1}$ Department of Life-sciences, Dibrugarh University, Dibrugarh-786 004, Assam, India \\ pubalibhuyan14feb@gmail.com \\ ${ }^{2}$ Department of Statistics, Dibrugarh University, Dibrugarh-786 004, Assam, India \\ rahmantousifur2018@gmail.com \\ ${ }^{3}$ Department of Zoology, D.R. College, Golaghat-785 621, Assam, India \\ rimen11@gmail.com
}

\begin{abstract}
The study was undertaken to understand the current JE scenario of Sivasagar, develop awareness and the importance of community participation. A questionnaire based cross-sectional survey was carried out by visiting Japanese encephalitis Patients from 2015 to 2019 to study epidemiology, sociodemographic status and the knowledge of people about the disease . Chi-square test was performed to evaluate the association among variables with significance level of $95 \%$. Total 256 participants were interacted. $62 \%$ have lack of knowledge on vectors, $73 \%$ are unaware about proper symptoms and $69 \%$ have partial information on transmission cycle. The epidemic season for JE is from April to August of every year. The majority of infections occur in rural areas $77 \%$. All ages are at risk. $64 \%$ of the respondents showed positive attitude towards community participation. The association between knowledge - Attitude is statistically significant (P-value .00001). Vaccination, control of vectors, and personal protection are the preventive measures. Identification of geographic locations of occurrence of disease, then a conversation with the patient and family members regarding clinical symptoms, their sociodemographic status, and knowledge regarding JE is important for the control of the disease.
\end{abstract}

KEYWORDS: Japanese encephalitis, Knowledge, Attitude, community, Sivasagar

\section{INTRODUCTION}

Mosquito-borne disease Japanese Encephalitis (JE) is the most important viral encephalitis in India being major public health concerns in the north-eastern state of Assam, deterring equitable socio-economic and industrial development ${ }^{7}$. Assam is the worst affected state contributing to $>36 \%$ of the total JE caseload of the country ${ }^{12}$. $\mathrm{JE}$, formerly endemic in upper Assam, is currently spreading fast across the state, with confirmed cases and a high case-fatality rate affecting all ages. The infection in the brain is caused by a flavivirus that is transmitted by the mosquito Culex vishnui group 9 . Pigs and birds, particularly the birds belonging to the family Ardeidae (e.g. cattle egrets, pond herons, etc.) are the natural hosts. The virus can also infect other vertebrates like birds and pigs. Pigs and wild birds are reservoirs of infection and pigs are called amplifier hosts in the transmission cycle 8 Man and horse are dead-end hosts. Those mosquitoes are prolific breeders in rice fields, irrigation channels, other small water collections like ponds, ditches, swamps, 
mud pools with vegetation, and mostly associated with rice agro-ecosystem ${ }^{16}$. Japanese encephalitis is numerically one of the most important causes of viral encephalitis worldwide, with an estimated 50,000 cases and 15,000 deaths annually 2 . About one-third of patients die and half of the survivors have severe neuropsychiatric sequelae. It is primarily a childhood disease because people develop immunity through exposure. Patients develop acute fever, headache as symptoms of JEV. Altered sensorium lasting $>6 \mathrm{hr}$ begins by the third to fifth day. The other symptoms include convulsions, altered sensorium, unconsciousness, coma, speech impairment, and more commonly behavior abnormalities ${ }^{7}$. All patients presenting with neuropathy are thus broadly categorized as Acute Encephalitis Syndrome (AES) unless confirmed for JE by detection of immunoglobulin $\mathrm{M}$ ( $\operatorname{IgM})$ antibodies in serum and cerebrospinal fluid using IgM antibody capture enzyme-linked immunosorbent assay (MAC ELISA) ${ }^{7}$. No specific treatment is available for $\mathrm{JE}^{8}$. Vaccination and vector control are the only available preventive measures to control the disease ${ }^{12}$. Control of the disease requires robust disease surveillance and integrated vector management. Sivasagar is one of the most endemic districts in Assam, India. The earliest records of Sivasagar were high risk with a history of repeated JE outbreaks and deaths (data source: District Health Society, Sivasagar, Assam). This is mainly due to the high prevalence of vectors (mosquito) and their amplifying hosts. Moreover, Sivasagar is full of wetlands and many big ponds where migratory birds often harbor. A vast majority of the population in Sivasagar is rural (>90\%) and an estimated $48 \%$ of the population lives below the poverty line. The climate of Sivasagar is typically subtropical, with hot and humid summers and severe monsoons followed by mild winters. The region receives heavy rainfall (2-3 m annually) and high relative humidity (60-80\%). Throughout the year is conducive to the proliferation and longevity of disease vectors, permitting active transmission of the virus

\section{MATERIALS AND METHODS}

Survey design: The study was a descriptive cross-sectional study and it is based on both primary and secondary data. The study was carried out by visiting house to house from January 2019 to February 2020. We have interacted with all JE patients from 2015 to 2019 and the head of the family. as per linelist received from District Health Society, Sivasagar. Study design was simple by interaction only. Data have been collected using pre-designed questionnaires designed from various published sources and research journals ${ }^{1,23}$. There are total 28 numbers of assessment questions covering the demographic situation, knowledge and attitude of the studied population. The Consent was taken before interaction. The interviewers were briefed regarding the objective and outcomes of the research before data collection. We have collected 
the environmental, social and demographic conditions of the house. We assumed 'don't know' as the answer 'No'.

Data analysis: All collected data are compiled using Microsoft office excels. The Samples are described using frequency and percentage in tables. Subsequently, results were analyzed using statistical tools. The chi- square test was used to investigate the association among study variables. A p-value of less than 0.05 was considered statistically significant.

\section{RESULTS AND DISCUSSION}

A total of 256 persons were interviewed. The case fatality rate has been declining gradually which is a good sign for the entire community. Table 1 illustrates the JE scenario from 2015 to 2019.As observed the different parameters of JE cases in table 2, Males (61\%) are more vulnerable than females (31\%). The majority of cases occur in people above the age of $15(60 \%)$. A significant number of JE cases were observed in children below age 15

Table 1: Table showing JE case burden from 2015 to 2019 in Sivasagar

\begin{tabular}{|l|c|c|c|c|}
\hline S1 no. & Year & No.of cases & No. of death & Case Fatality Rate \\
\hline 1 & 2015 & 67 & 17 & $25.4 \%$ \\
\hline 2 & 2016 & 38 & 9 & $23.7 \%$ \\
\hline 3 & 2017 & 64 & 14 & $21.9 \%$ \\
\hline 4 & 2018 & 41 & 10 & $24.4 \%$ \\
\hline 5 & 2019 & 46 & 6 & $13 \%$ \\
\hline
\end{tabular}

years $(40 \%)$. But the vaccination status was found poor both in adults and children (adult vs children, $26 \%$ vs $43 \%$ ). There were occurrences of JE cases throughout the year but the trend increases from April to September with a peak in June- July coinciding with monsoon and post-monsoon. Figure 1 represents the seasonal variation of JE cases. In table 3, we were used to accessing the knowledge of the respondents. We found that the majority of respondents are unaware of the basic knowledge on vectors (62\%), mosquito breeding (47\%), proper symptoms (73\%), preventive measures (55\%), available medical facilities $(66 \%)$, and availability of vaccines in health centers $(88 \%)$. Among them $62 \%$ know that the reservoirs of the virus are migratory birds or pigs, $69 \%$ had partial information on the transmission cycle and $63 \%$ had correctly answered us about the biting preference of the mosquitoes. Most of the family had no previous records of patients suffering from JE. Only $2 \%$ of families were experienced earlier. Demographic characteristics of participants are detailed in table 4. It has been found that respondents' knowledge and 
Table 2: Table showing different parameters of JE cases from 2015 to 2019 in Sivasagar

\begin{tabular}{|c|c|c|c|c|c|c|}
\hline Year & Male & Female & Patient's age $>15$ & Patient's age <15 & Vaccinated adult & Vaccinated children \\
\hline 2015 & $64 \%$ & $36 \%$ & $31 \%$ & $69 \%$ & $10 \%$ & $6 \%$ \\
\hline 2016 & $63 \%$ & $37 \%$ & $61 \%$ & $39 \%$ & $21 \%$ & $42 \%$ \\
\hline 2017 & $70 \%$ & $30 \%$ & $63 \%$ & $38 \%$ & $22 \%$ & $19 \%$ \\
\hline 2018 & $46 \%$ & $54 \%$ & $80 \%$ & $20 \%$ & $17 \%$ & $12 \%$ \\
\hline 2019 & $56 \%$ & $44 \%$ & $79 \%$ & $21 \%$ & $9 \%$ & $16 \%$ \\
\hline
\end{tabular}

Table 3: Knowledge of respondents about the disease $(n=256)$

\begin{tabular}{|l|c|c|}
\hline \multicolumn{1}{|c|}{ Variables } & $\begin{array}{c}\text { Correct } \\
\text { response (\%) }\end{array}$ & $\begin{array}{c}\text { Incorrect } \\
\text { response (\%) }\end{array}$ \\
\hline Knowledge on vector & $38 \%$ & $62 \%$ \\
\hline Knowledge on vector mosquito breeding & $53 \%$ & $47 \%$ \\
\hline Previous Knowledge on symptoms of JE & $27 \%$ & $73 \%$ \\
\hline Knowledge on preventive measures of JE & $45 \%$ & $55 \%$ \\
\hline Knowledge of Medical facilities of JE & $34 \%$ & $66 \%$ \\
\hline Knowledge on Vaccine availability in hospital & $12 \%$ & $88 \%$ \\
\hline $\begin{array}{l}\text { Knowledge of the reservoir of the virus } \\
\text { (pig or other migratory birds) }\end{array}$ & $62 \%$ & $38 \%$ \\
\hline Knowledge of the transmission cycle & $69 \%$ & $31 \%$ \\
\hline Knowledge on the biting habit of the mosquito (day or night) & $63 \%$ & $37 \%$ \\
\hline Any person in the family earlier suffered from this disease & $2 \%$ & $98 \%$ \\
\hline
\end{tabular}

sociodemographic profile are closely related. $67 \%$ of the patients were from rural settings with poor drainage systems $(77 \%)$ and unhygienic conditions (59\%). During the visit to households, we have observed the water logged surroundings of the houses and the environmental settings of their houses were covered with bamboos (35\%), associated rice fields $(41 \%)$, and wetlands $(6 \%)$ where migratory birds harbor in monsoon months. Pig farming plays an important role in the economy of households in rural areas. $18 \%$ of houses were found having piggeries less than one kilometer from their house surrounding. The sources of drinking water were found tubewell (45\%) and Pond (33\%) as more reliable sources of drinking water. The educational qualifications of most of the patients are under the $10^{\text {th }}$ standard $(67 \%)$. Knowledge about JEV is significantly higher in young groups (16-40 years). News paper, Radio or 
Table 4: Sociodemographic variables of Respondents

\begin{tabular}{|c|c|c|}
\hline Variables & Categories & Participants (\%) \\
\hline \multirow[t]{2}{*}{ Education } & Under $10^{\text {th }}$ standard & $67 \%$ \\
\hline & Above $10^{\text {th }}$ standard & $33 \%$ \\
\hline \multirow[t]{6}{*}{ Occupation } & Govt. employee & $8 \%$ \\
\hline & Own business & $7 \%$ \\
\hline & Farmer & $18 \%$ \\
\hline & homemaker & $22 \%$ \\
\hline & student & $36 \%$ \\
\hline & Daily rated labor & $9 \%$ \\
\hline \multirow[t]{2}{*}{ Marital status } & Married & $60 \%$ \\
\hline & Unmarried & $40 \%$ \\
\hline \multirow[t]{2}{*}{ Place of admissionto hospital } & Govt. hospital & $82 \%$ \\
\hline & Private hospital & $18 \%$ \\
\hline \multirow[t]{2}{*}{ House sitting } & Rural & $67 \%$ \\
\hline & Urban & $33 \%$ \\
\hline \multirow[t]{2}{*}{ Water drainage of household } & Good & $23 \%$ \\
\hline & Poor & $77 \%$ \\
\hline \multirow[t]{2}{*}{ House surrounding } & Hygienic & $41 \%$ \\
\hline & Unhygienic & $59 \%$ \\
\hline \multirow[t]{3}{*}{ Drinking water of household } & Tape & $21 \%$ \\
\hline & Pond & $33 \%$ \\
\hline & Tubewell & $45 \%$ \\
\hline \multirow[t]{4}{*}{ The animal associated with the house } & Pig & $18 \%$ \\
\hline & Cattle & $38 \%$ \\
\hline & Poultry & $28 \%$ \\
\hline & No animals & $16 \%$ \\
\hline \multirow[t]{4}{*}{ The reservoir of vector nearby the house } & Bamboo cultivation & $35 \%$ \\
\hline & Associated with paddy field & $41 \%$ \\
\hline & Piggery & $18 \%$ \\
\hline & wetland & $6 \%$ \\
\hline
\end{tabular}

$101 ・ J$. Adv. Zool. $2021: 42(1)$ 
Table 5: Attitude of respondents in relation to $\mathrm{JE}$

\begin{tabular}{|l|c|c|}
\hline Variables & Agreed (\%) & Disagree (\%) \\
\hline JE is a serious illness & 100 & 0 \\
\hline It is preventable & 61 & 39 \\
\hline Residents of every family have a risk of getting JE & 66 & 34 \\
\hline Control of mosquito can prevent it & 67 & 33 \\
\hline Vaccination can prevent it & 58 & 32 \\
\hline $\begin{array}{l}\text { Stagnant water and unhygienic conditions are the main } \\
\text { cause of this disease }\end{array}$ & 69 & 34 \\
\hline Personal protection measures can prevent it & 66 & 36 \\
\hline Community participation is required in controlling JE & 64 & 34 \\
\hline
\end{tabular}

*The association between knowledge-attitude was estimated using chi-square test (P-value .00001 with $9 \mathrm{df})$.

TV and also mobile internet facilities are helping in this regard. If we see from the view of occupation, it seems that Homemakers and farmers (18\%) are mostly affected. This may be due to farmers used to spend most of the time in their farms without properly covering the body. As the mosquito is exophilic and zoonotic they can easily bite a person in such a situation. The information about attitude of participants is detailed on table 5. People showed a positive attitude towards JE and its control. All respondents agreed it was a serious illness and $61 \%$ consider it as preventable. $58 \%$ of the respondents favor vaccination while $31 \%$ did not consider the stagnant water and unhygienic condition as a factor for transmission of the disease. Most of the respondents $(64 \%)$ agreed that community participation required for control of JE. Chisquare test between Knowledge and
Attributes are measured. Since P- Value < .05 , the association between knowledgeattitude was statistically significant. The knowledge of JE and its control among the community in Sivasagar is not good as per the survey. But the attitude was satisfactory. Survey was conducted earlier on community participation in Eastern U.P. and they had experienced with low community participation also ${ }^{13,21}$. Dissemination of all evaluated data to the community is necessary as a pre-preparedness to minimize the disease burden. Conveying simple information regarding causes, transmission, and prevention from mosquito bites are required to sensitize the community. Studies showed the JE caseload in the pediatric groups and found that children mostly reported from rural areas and belong to low social groups ${ }^{11}$. This may be due to favorable epidemiological factors, nonuse of 
preventive measures, and outdoor playing habits of children. Awareness needs to be developed on personal protection against mosquito bites and use of long sleeves, shirts, and trousers for 24 hours especially during dusk hours. As per the operational guidelines for the management of $\mathrm{AES} / \mathrm{JE}$ from NVBDCP, the main cause of high Fatality/Mortality is transporting patients over long distances without proper medical care. Transport of patients to the nearest hospital and early referral of cases should be promoted. The treatment protocol is the same and available in all health institutions. As most of the JE patients were from the rural environment and below the poverty level, they prefer government facilities. Our results also showed that $82 \%$ of total patients had used govt. hospitals for treatment. JE case incidence in tertiary care hospital in Dibrugarh was studied in 2014 and found that patients in Upper Assam were mainly from rural areas and clustering of cases in the rainy season ${ }^{14}$. Here, our study wants to highlight that the government and other concerned authorities should take essential measures to ensure health facilities are easily accessible to all.It is a disease largely of rural areas and cases are corresponding with heavy rainfall ${ }^{7}$. Communities have to take few steps like the cleanliness of their surroundings for reducing places that favor mosquito breeding like pools, drainage, water collecting pots, etc. Studies were done on the influence of rainfall on JE cases in Lakhimpur and found the vector density has its peak during monsoon months during rainfall ${ }^{20}$. Biological control of mosquitoes can be promoted. Study on the larvivoracity and habitat distribution of native fishes was done in 2018 in Ranchi ${ }^{6}$. Similar studies were done in Karimnagar, Andhra Pradesh and Assam ${ }^{18,17}$. Local larvivorous fishes can be released to stagnant pools, ponds, streams, etc. As the rice field is the main breeding spot for the vector mosquito, we should not destroy the diversity in rice fields. The food chain can help us in lowering the larval density. Many leading researchers in Assam have reported in their Research that many local plants having insecticidal properties and resins can be effectively used against larvae and adults of the vector. The biocontrol potential of plant parts against Aedes aegypti and Culex quinquefasciatus in laboratory conditions have been studied and established ${ }^{5,4}$. The use of eco-friendly mosquito repellants can be beneficial. The relative abundance of mosquito species and seroprevalence of JE in pigs in order to draw an epidemiological association with reported human cases in Assam was checked ${ }^{3}$. They observed a good correlation between mosquito number and JEV positivity in pigs/humans and between pigs and human cases. They stated that the human population in Sivasagar was at higher risk for JE infection than in Kamrup rural district in Assam. Pig seropositivity may help in predicting JEV outbreak in humans. Pigs/piggeries should be kept away from residual premises. Pigs should be covered by a mosquito net if possible. 
Government programs like awareness meetings, public address systems required to aware the community. Behaviors change programmers' like street plays, awareness meetings, audio-visual media, print media can be used to educate the public. Use of bed-net while sleeping preferably impregnated bed nets with pyrethroids are beneficial. Students can also organize symposiums, seminars, and debates on preventive aspects of Vector-Borne Diseases and also can participate in the JE vaccination Campaign and carrying out weekly cleaning drives on school premises, checking water containers for mosquito breeding, etc. All those strategies were supported by many researchers in their earlier works. The effectiveness and impact of immunization among adults was studied in Sivasagar from 2012 to 2018 and the result was encouraging. JE vaccination program was started in Sivasagar (first time in Assam, India) in 2006 among the pediatric population (1-15 years) (data source: District Health Society, Sivasagar, Assam). SA1414-2 is a safe, effective, and affordable vaccine used by NVBDCP and it has been used in many districts in Assam ${ }^{12}$. Effectiveness of one dose was found $80 \%$ and two doses were $97.5 \%$ by earlier researchers ${ }^{10}$. Administration to children is in the annual vaccination program. In our study, most of the people even don't know about their vaccination status on JE. So, Community participation is required for good coverage of vaccination programs. An earlier study in the Darrang district also showed concern about the availability of vaccines in the district ${ }^{1}$. Our survey assumed high availability of vaccines can be one of the most effective ways to control the spread of JE.

\section{CONCLUSION}

Intersectoral coordination required in this regard. Departments like Health \& Family Welfare Department, Veterinary Department, Social Welfare Officer, Public Health Engineering, Irrigation Department, Agriculture Department, Fishery Department, Forest Department, Education Department, Tea Gardens and plantation all have to work in coordination to minimize the risk of JEV transmission. A well-planned mass education and communication strategy can further enhance people's attitudes and practice towards the prevention of JEV. Climate change may also influence the agro practices and migration patterns of birds, which may result in the introduction of JEV to new areas. Environmental analyses for the vector and virus reservoirs are the most important factors. Multiple linkages to determinants such as poverty, socioeconomic status, gender, environment, and population distribution, make it a greater developmental issue than just a zoonotic disease.

\section{Funding}

This research did not receive any specific grant from funding agencies in the public, commercial, or not-for-profit sectors. 


\section{Declaration of competing interest}

The authors declare that they have no conflict of interest.

\section{ACKNOWLEDGMENTS}

Authors sincerely acknowledge the District Health Society and NVBDCP Sivasagar, Assam, India for providing the Line list of JE cases from 2015 to 2019. They are also thankful to the field level health workers of NVBDCP, Sivasagar, Assam without their help it would not be possible to complete the study.

\section{REFERENCES}

1. Ahmad, A., U. Muhammad, U. Khan, S. Malik, S.Q. Jamshed, L.J. Gogoi, M.Kalita \& A.P. Sikdar, 2017. Community knowledge and attitude towards Japanese encephalitis in Darang, India: a cross-sectional study. Annals of Tropical medicine and public health, 10(2): 377-383.

2. Ahmad, A., M.U. Khan, L.J.Gogoi, M. Kalita, A.P. Sikdar, S. Pandey \& S. Dhingra, 2015. Japanese encephalitis in Assam, India: Need to increase healthcare workers' understanding to improve health care. PLoS One, 10(8): 111.

3. Baruah, A., R.A. Hazarika, N.N. Barman, S. Islam \& B.R. Gulati, 2018. Mosquito abundance and pig seropositivity as a correlate of Japanese encephalitis in human population in Assam. India.J Vector Borne Dis., 55(4): 291-296.

4. Borah, R., M.C. Kalita, A. Kar \& A.K. Talukdar, 2010. Larvicidal efficacy of Toddalia asiatica (Linn.) Lam against two mosquito vectors Aedes aegypti and Culex quinquefasciatus. African Journal of Biotechnology, 9(16): 2527-2530.

5. Dahutia, C., D.R. Bhattacharyya, S.K. Sharma
\& P.K. Mohapatra, 2015. Larvicidal activity of few select indigenous plants of North East India against disease vector mosquitoes (Diptera : Culicidae ). Tropical Biomedicine, 32(1); 17-23.

6. Das, M.K., M.R.K. Rao \& A.K. Kulshreshtha, 2018. Native larvivorous fish diversity as a biological control agent against mosquito larvae in an endemic malarious region of Ranchi district in Jharkhand. India. Journal of Vector Borne Diseases, 55(1): 34-41.

7. Dev, V., V.P. Sharma \& K. Barman, 2015. Mosquito-borne diseases in Assam, north-east India: current status and key challenges. WHO South-East Asia Journal of Public Health, 4(1): 20-29.

8. Dey, A.K. \& A. Chakrabarty, 2019. Epidemiological study on trends of Japanese encephalitis and acute encephalitis syndrome in Cachar District of Assam. Journal of Evaluation of Medical and Dental Sciences, 8(21): 1719-1725.

9. Dhiman, S., B. Rabha , P.K. Talukdar, N.G. Das, K. Yadav, I. Baruah, L. Singh \& V. Veer, 2013. DDT \& deltamethrin resistance status of known Japanese encephalitis vectors in Assam, India. Indian J Med Res, 138(6): 114120.

10. Hennessy, S., Z. Liu, T.F. Tsai, B.L. Strom, C.M. Wan, H.L. Liu et al., 1996. Effectiveness of live-attenuated Japanese encephalitis vaccine (SA14 -14-2): a case-control study. Lancet, 347(9015): 1583-1586.

11. Kakoti, G., P. Dutta, B.R. Das, J. Borah \& J. Mahanta, 2013. Clinical Profile and Outcome of Japanese Encephalitis in Children Admitted with Acute Encephalitis Syndrome. BioMed Research International, pp. 1-5.

12. Khan, S.A., P. Choudhury \& H. Kaur, 2020. Effectiveness of Japanese encephalitis vaccine SA 14-14-2 and impact of immunization among adults in Assam, India. International Journal of Infectious Diseases, 101(1): 482.

13. Kumari, R. \& P. Joshi, 2012. A review of 
Japanese encephalitis in Uttar Pradesh, India. WHO South Asia Journal of Public Health, 1(4): 374-395.

14. Medhi, M., L. Saikia, S.J. Patgiri, V. Lahkar, M.E. Hussai \& S. Kakati, 2017. Incidence of Japanese Encephalitis amongst acute encephalitis syndrome cases in upper Assam districts from 2012 to 2014: A report from a tertiary care hospital. India J Med Res, 146(2); 267-271.

15. Operational guidelines Clinical Management of Acute Encephalitis syndrome including Japanese encephalitis, 2005. The Directorate of NVBDCP, Delhi, pp. 1-20

16. Phukan, A.C., P.K. Borah \& J. Mahanta, 2004. Japanese encephalitis in Assam, northeast India. Southeast Asian Journal of Tropical Medicine Public Health, 35(3): 618-622

17. Phukon, H.K. \& S.P. Biswas, 2013. An investigation on Larvicidal Efficacy of some indigenous Fish Species of Assam, India. Advances in Bioresearch, 4(3): 22-25.

18. Rao, R., 2014. A study on larvivorous fish species efficacy of lower Manair dam at Karimnagar, Andhra Pradesh, India.
Advances in Applied Science Research, 5(2): 133-143.

19. Sharma, J., M.K. Baruah, A. Pathak, S.A. Khan \& P. Dutta, 1996 . Epidemiology of Japanese encephalitis cases in Dhemaji district of Assam. India. Ann. Biol. Res, 5: 50-54.

20. Sharma, J. \& M. Soni, 2015. Influence of rainfall on Incidence of AES/JE cases - A study from Lakhimpur district of Assam in 2011-12. Applied Research Journal, 1(4): 182-185.

21. Srivastava, P., A. Singh, A.K. Srivastava, A.P. Singh \& D. Prakash, 2014. Role of Education and counseling for the Prevention of Japanese Encephalitis in the Eastern U.P., India. Epidemiol, 4(3): 1-6.

22. Transmission of JE Virus. Centre for Disease Control and prevention. Accessed 10 January, 2015.

23. Yadav, S. \& S. Ahmed, 2017. An assessment of community participation in control and prevention of Japanese encephalitis in rural Uttar Pradesh. International Journal of Medical Science and Public Health. 6(11): 1614-19. 
